\title{
Interactive effects of shock intensity and delay of reinforcement on escape conditioning'
}

\author{
R. W. BELL, J. C. NOAH AND J. R. DAVIS, JR. \\ NORTHERN ILLINOIS UNIVERSITY
}

\begin{abstract}
A 3 (levels of shock) by 4 (delays of shock termination) design investigated effects of delay of reinforcement in escape conditioning in 60 rats in a 2-compartment shuttle box. Different delay gradients were obtained under different levels of shock intensity $(p<.01)$, with all delay groups showing marked inhibition of performance when compared to non-delay groups $(p<.01)$ 。 The significant drive level (controlled by shock intensity) by delay of reinforcement interaction is inconsistent with results of investigations varying degree of food deprivation and delay of food reward (Ramond, 1954; Renner, 1963), and suggest that Spence's (1956) theory of delay of reinforcement in appetitive learning cannot be generalized to aversive conditioning.
\end{abstract}

\section{Introduetion}

It has been established that typically response strength declines as a monotonic function of temporal delay of reinforcement following occurrence of a response (Wolfe, 1934; Perin, 1943), and that delay of secondary reinforcement produces a similar effect (Perkins, 1947)。Kamin (1957a, 1957b) has shown that delay of CS termination in an instrumental avoidance learning task significantly retards the occurrence of an initial avoidance response and the frequency of avoidance responses, the effect being a monotonic function of delay. The present study is an investigation of the effects of delay of UCS termination following a response in an escape conditioning task to determine if delay of primary reinforcement in an aversive conditioning task produces the same effect as found in Kamin's $(1957 a, 1957 b)$ study of delay of secondary reinforcement. Intensity of UCS is also varied to determine if Spence's (1956) theoretical position relating drive level and delay of reinforcement additively can be generalized from learning under conditions of positive reinforcement, as in Ramond's (1954) and Renner's (1963) studies, to an escape conditioning paradigm.

\section{Method}

Experimental Design and Subjects

The experimental design was a 3 by 4 factorial design, in which three levels of shock intensity (.25 ma, $.50 \mathrm{ma}$ and $1.0 \mathrm{ma}$ ) were combined with four delays of shock termination $(0,1.25,2.50$ and 5.00 sec.). Ss were 60 naive, female hooded rats of the Long-Evans strain. All Ss were approximately 80 days of age at the beginning of the experiment. Five Ss were randomly assigned to each of the 12 treatment combinations. Apparatus

The apparatus was a two-compartment shuttle box, constructed of white Marlite with a grid floor. Each compartment measured 15 in by 13 in by 16 in high. Separating the two compartments was a 3-in barrier and a vertically-opening door, which was operated by a motor and electro-magnet mounted on top of the apparatus. The grid floor was activated by a LVE 1531 shock-scrambler. Three Sylvania PCK-10 conductors were mounted in the wall on either side of the barrier to detect Ss response and control the door closing, a Foringer interval timer controlling offset of shock and a Standard .01'"' timer, used to record response latency. Procedure

Approximately $1 \mathrm{~min}$. after placing a $\mathrm{S}$ in one of the compartments, $\mathrm{E}$ initiated the trial via a remote switch. The switch simultaneously activated the grid floor with the specified shock intensity, opened the door separating the two compartments, and started the .01'"' timer. When the $S$ jumped the barrier the photo-electric beam was broken, stopping the latency timer, closing the door, and starting the interval timer, which in turn terminated the shock after the prescribed delay. If $\mathrm{S}$ failed to respond within $180 \mathrm{sec}$. the trial was terminated and an arbitrary latency of $180 \mathrm{sec}$. recorded. On alternate trials each compartment was successively a starting or escape chamber.

Ten trials per day with an intertrial interval of 30 sec. were run. Possible diurnal cyclic confounding was controlled by counter-balancing time of testing among Ss. Mean response latency per block of 10 trials was recorded for each $\mathrm{S}$.

Following 10 days of acquisition trials, five massed extinction trials were conducted on each of two successive days. Mean latencies for the first five and second five extinction trials were recorded for each $\mathrm{S}$.

\section{Results}

Mean daily latencies were transformed to running speeds via a reciprocal transformation.

Figures 1 and 2 present acquisition of running speed as a function of shock intensity $(F=24.85$; $d f=2 / 432$; $\mathrm{p}<.01)$ and delay of UCS termination $(\mathrm{F}=\mathbf{2 7 . 5 4}$; $\mathrm{df}=3 / 432 ; \mathrm{p}<.01)$, respectively. The groups range themselves in the expected rank orders. Figure 2 reveals the extremely inhibiting effect of even brief delays of UCS termination upon running speed, and suggests that little learning occurred under conditions of 1.25 and $2.50 \mathrm{sec}$. delay, with no learning under 5.0 sec. delay. (It might be noted that the triple order interaction of shock intensity by delay of reinforcement by trials barely missed significance at the .05 level. An examination of the data revealed consistently slow running speeds for the low shock-long delay groups and highly variable running speeds from trial to trial 
Fig. 1.

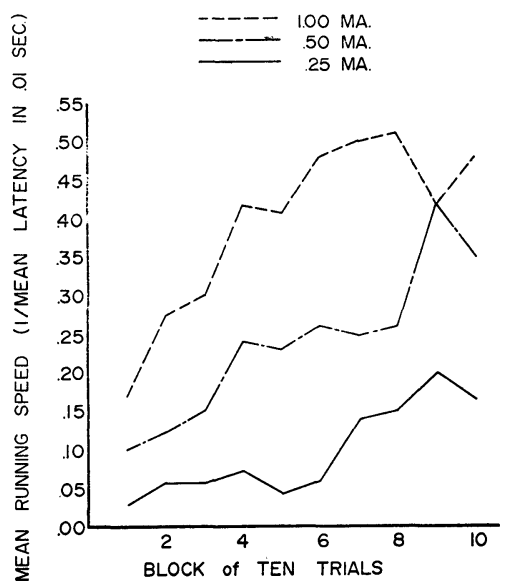

for the high shock-long delay group.)

Figure 3 shows the shock intensity by delay of reinforcement (averaged across trials) interaction ( $F=4.82$; $\mathrm{df}=6 / 432 ; \mathrm{p}<.01)$. As shock level increases, the delay of reinforcement gradient shifts from a shallow linear function to a steep quadratic function. The major source of the significant interaction appears to be the differential effect of increased shock intensity on the no-delay groups, although the $1.0 \mathrm{ma}$ shock also appears to be differentially affecting the $1.25 \mathrm{sec}$. delay Ss.

The triple order interaction obtained with the extinction scores $(F=2.34 ; d f=6 / 432 ; p<.05)$ was produced by the 1.0 ma-no delay $\mathrm{Ss}$, which exhibited initially rapid responses followed by rapid extinction. All other Ss extinguished almost spontaneously, typically failing to respond at all after the first two or three extinction trials.

\section{Diseussion}

The data satisfactorily demonstrate an empirical gradient effect of delay USC termination on escape learning grossly similar to those obtained under conditions of delay of food reward (e.g. Wolfe, 1934; Perkins, 1947) and delay of CS termination in avoidance learning (Kamin, 1957a, 1957b). However, the present data suggest a much greater inhibitory effect on running speed of very brief days of reinforcement, where

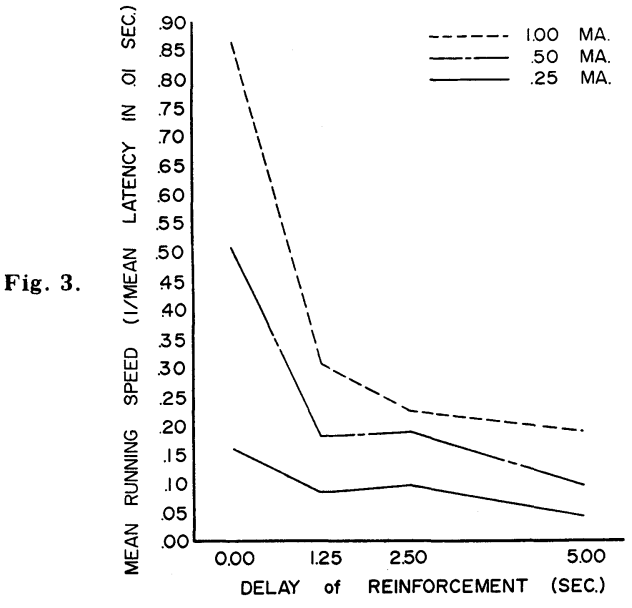

Fig. 2 .

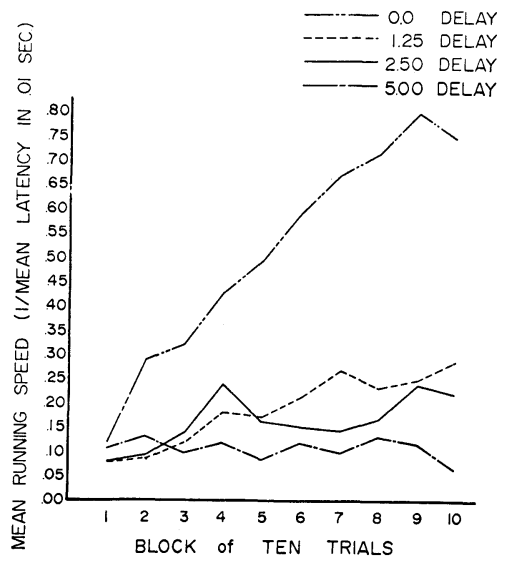

reinforcement consists of termination of shock, than has characteristically been found with brief delays of primary positive reinforcement or secondary aversive stimuli. A possible reason for this inhibitory effect is that the experimental paradigm placed Ss is what was essentially an avoidance-avoidance conflict. Consistent with this interpretation was the observation that many Ss, particularly those under conditions of intense shock and long delay, would cling to the top of the barrier separating the two grids, even though the barrier was also electrified.

Of particular interest in the present study is the finding of a significant drive level (controlled by shock intensity) by delay of reinforcement interaction. These results are inconsistent with results of investigations varying degree of food deprivation and delay of food reward (Ramond, 1954; Renner, 1963), which have found these two variables to operate independently of one another. The results suggest that Spence's (1956) theory of delay of reinforcement in appetitive learning, which assumes an additive relationship between drive level and delay of reinforcement, cannot be generalized to aversive conditioning.

\section{References}

Kamin, L. J. The gradient of delay of secondary reward in avoidance learning. J. comp. physiol. Psychol., 1957a, 50, 445-449.

Kamin, L. J. The gradient of delay of secondary reward in avoidance learning tested on avoidance trials only. J. comp. physiol. Psychol., 1957b, 50, 450-456.

Perin, C. T. A quantitative investigation of the delay-of-reinforcement gradient. J. exp. Psychol., 1943, 32, 37-51.

Perkins, C. C. The relation of secondary reward to gradients of reinforcement. J. exp. Psychol., 1947, 37, 377-392.

Ramond, C. K. Performance in instrumental learning as a joint function of delay of reinforcement and time of deprivation. $J$. exp. Psychol., 1954, 47, 248-250.

Renner, K. E. Influence of deprivation and availability of goal box cues on the temporal gradient of reinforcement. J. comp. physiol. Psychol., 1963, 56, 101-104.

Spence, K. W. Behavior theory and conditioning. New Haven: Yale University Press, 1956.

Wolfe, J. B. The effect of delayed reward upon learning in the white rate. J. comp. Psychol., 1934, 17, 1-21.

\section{Note}

1. Based in part on a thesis submitted to the faculty of Northern Illinois University in partial completion of the requirements of the M. A. degree by J. C. Noah. 